\section{Acolhimento e transformações no processo de trabalho de enfermagem em unidades básicas de saúde de Campinas, São Paulo, Brasil}

\author{
Receptiveness and changes in the nursing \\ work process in healthcare units in Campinas, \\ São Paulo, Brazil
}

\author{
${ }^{1}$ Faculdade de Ciências \\ Médicas, Universidade \\ Estadual de Campinas, \\ Campinas, Brasil. \\ Correspondência \\ M. L. S. Takemoto \\ Departamento de \\ Enfermagem, Faculdade \\ de Ciências Médicas, \\ Universidade Estadual \\ de Campinas. \\ Rua Tessalia Vieira de \\ Camargo 126, Cidade \\ Universitária Zeferino Vaz, \\ C.P. 6111, Campinas, SP \\ 13083-970, Brasil. \\ mairalibertad@uol.com.br
}

\begin{abstract}
This article describes changes in the nursing work process resulting from implementation of the process referred to as "receptiveness", following introduction of the Paidéia Family Health Program in health care units in Campinas, São Paulo, Brazil, since 2001. Data were collected through participant observation and semistructured interviews to examine the nursing work process, specifically in relation to "receptiveness". The analysis was based on two possible definitions of "receptiveness": as an attitude towards users and their needs, and as a device for reorganizing the work process. The study also analyzes "receptiveness" in relation to: organization of the work process, guarantee of accessibility, expanded demands on the health service and health team, changes in the nursing work process, humanization, and bonding.
\end{abstract}

User Embracement; Nursing; Family Health Program
Maíra Libertad Soligo Takemoto 1 Eliete Maria Silva 1

O presente artigo relata as transformações no trabalho da enfermagem com a incorporação do acolhimento no processo de implementação do Projeto Paidéia de Saúde da Família na Secretaria Municipal de Saúde de Campinas, São Paulo, Brasil, a partir de 2001 1. Partimos da reflexão sobre a produção recente sobre o acolhimento e, a seguir, detalhamos os resultados encontrados.

Entendemos o trabalho em saúde como um modo de trabalhar específico, em que o consumo se dá imediatamente no momento da produção. Sendo assim, temos a construção de um espaço intercessor nos momentos assistenciais da produção de serviços de saúde entre usuários e trabalhadores, em que ambos vêm instituindo necessidades e modos capturados de agir, num jogo de encontro e negociação de necessidades, o que determina uma maior autonomia no agir dos trabalhadores e equipes 2 .

É com base na noção de espaço intercessor como encontro e negociação entre trabalhadores e usuários que situamos o acolhimento, enquanto uma etapa do processo de trabalho e enquanto um modo específico de encontro. Vários autores conceituaram acolhimento e contribuem, em alguma medida, para sua operacionalização e estudo $3,4,5,6,7$.

Teixeira 6 é um dos autores que trabalha com a abordagem do acolhimento enquanto um modo de se relacionar com os usuários e o define como uma "rede de conversações". O autor propõe 
a adoção do termo acolhimento-diálogo para definir um tipo especial de conversa que se dá (ou deveria se dar) no interior dos serviços de saúde e que ele considera como "uma espécie de mola mestra da lógica tecnoassistencial e, mesmo, como um dispositivo indispensável para o bom desempenho da rede tecnoassistencial de um serviço de saúde" 6 (p. 99).

A idéia é de que o acolhimento tem um papel fundamental na rede de conversações que constitui um serviço de saúde, na verdade, ocupando todos os lugares e tendo o papel de receber e interligar uma conversa à outra, conectando os diferentes espaços de conversa, e se dá em qualquer encontro trabalhador-usuário, em qualquer dessas conversas. Os trabalhadores continuamente acolhem novas possíveis demandas e, quando necessário, "convidam o usuário a freqüentar outros espaços, a entreter outras conversas" 6 (p. 101).

O "acolhimento-diálogo" pode oferecer ao usuário maior possibilidade de trânsito pela rede e ocorre em todos os encontros assistenciais durante a passagem do usuário pelo serviço, porque se trata efetivamente da contínua investigação/elaboração/negociação das necessidades de saúde que podem vir a ser satisfeitas pelo serviço, processo que não deve deixar nunca de acontecer, tendo em vista que as necessidades não são imediatamente transparentes e nem jamais definitivamente definidas 6 .

Desse modo, entendemos, conforme Teixeira ${ }^{6}$, que o acolhimento não é necessariamente uma atividade em si, mas conteúdo de toda atividade assistencial, que consiste na busca constante de um reconhecimento cada vez maior das necessidades de saúde dos usuários e das formas possíveis de satisfazê-las, resultando em encaminhamentos, deslocamentos e trânsitos pela rede assistencial.

Esse entendimento aproxima-se do que Silva Jr. \& Mascarenhas 5 denominam de acolhimento como postura, que pressupõe uma atitude da equipe de comprometimento em receber, escutar e tratar de forma humanizada os usuários e suas necessidades, por meio de uma relação de mútuo interesse entre trabalhadores e usuários, estruturada enquanto "relação de ajuda", conforme Camelo et al. ?

Há ainda uma outra possibilidade de entendimento do acolhimento que Franco et al. 3 definem como a possibilidade de olhar para o processo de produção da relação entre usuário e serviço por intermédio da questão da acessibilidade, das ações de recepção dos usuários no serviço de saúde. Nesse sentido, o acolhimento aparece como uma etapa do processo, "um dispositivo a provocar ruídos sobre os momentos nos quais o serviço constitui seus mecanismos de recepção dos usuários" 3 (p. 39).

Os objetivos do acolhimento seriam, por essa perspectiva: ampliar o acesso dos usuários ao serviço, humanizar o atendimento e funcionar como dispositivo para a reorganização do processo de trabalho. De acordo com Silva Jr. \& Mascarenhas 5, o acolhimento, entendido como reformulador do processo de trabalho, pontua problemas e oferece soluções e respostas pela identificação das demandas dos usuários, rearticulando o serviço em torno delas.

Franco et al. 3 consideram que o acolhimento modifica radicalmente o processo de trabalho, em especial dos profissionais não médicos que realizam assistência, visto que a organização do serviço passa a ter a "equipe de acolhimento" como central no atendimento aos usuários. Abrese, supostamente, a possibilidade para que esses profissionais lancem mão de todas as tecnologias de sua "caixa de ferramentas" para receber, escutar e solucionar problemas de saúde trazidos pelos usuários.

O acolhimento configurar-se-ia, então, em uma etapa do processo de trabalho responsável pelo atendimento da demanda espontânea. A proposta de implantação do acolhimento analisada por esses autores, implementada no Município de Betim, em Minas Gerais, valia-se de alguns pressupostos básicos e buscava superá-los: demanda reprimida significativa, alta solicitação por consulta médica mesmo sem necessidade verificada, trabalho na unidade centrado na prática médica, baixo aproveitamento do potencial para assistência dos demais profissionais e deterioração da relação trabalhador-usuário, causada pela alienação do processo de trabalho 3 .

Os autores pontuam algumas mudanças operadas pela implementação do acolhimento especificamente no trabalho de enfermagem. A enfermeira, além de acolher, ficou responsável pela supervisão do atendimento realizado pelas auxiliares de enfermagem, pelas orientações sobre as condutas e utilização dos protocolos, elaborados pela equipe e que indicavam as condutas a serem tomadas diante das queixas mais comuns dos usuários que procuravam a unidade e as atribuições de cada membro da equipe.

De acordo com esses autores, a reorganização do trabalho com base no acolhimento resultou maior resolubilidade no trabalho da enfermeira na assistência, por conta da definição de protocolos de conduta que incluem a prescrição de vários medicamentos e exames, o que ainda favoreceu o fluxo dos usuários. Além disso, houve um aumento na autonomia da enfermeira, entendida aqui como " a condição de o profissional decidir sobre o seu trabalho, o exercício pleno do 
'saber fazer' no momento do procedimento assistencial" 3 (p. 45).

Com relação às auxiliares de enfermagem, os autores afirmam o seguinte: "seu trabalho anterior à implantação do acolhimento resumia-se às atividades próprias da sua função (curativo, injeção, vacina, distribuição de medicamentos) e apoio aos médicos. A Auxiliar de Enfermagem, ao contrário do que era no modelo anterior, deixa de ser apenas um acessório na organização do processo de trabalho na Unidade de Saúde, para assumir a plenitude da sua profissão em benefício do atendimento com qualidade" 3 (p. 45-6).

Os mesmos autores concluem que o acolhimento tem como resultado imediato esperado a reversão do modelo tecnoassistencial, mas pode ainda contribuir com o acúmulo de outros ganhos, já que tem potencial para reorganizar os serviços de saúde por intermédio do processo de trabalho, e construir dispositivos auto-analíticos e autogestionários, além de provocar mudanças estruturais na forma de gestão do serviço.

Temos, então, duas possibilidades de entendimento do acolhimento expostas aqui: uma como postura diante do usuário e suas necessidades, de contínua investigação e negociação das necessidades de saúde e modos de satisfazê-las em todos os momentos do processo de produção de serviços de saúde. E outra, como dispositivo capaz de reorganizar o trabalho na unidade, uma etapa do processo de trabalho que tem como objetivo atender à demanda espontânea, aumentando o acesso e humanizando as ações receptoras dos usuários no serviço.

Entendemos que elas não são excludentes entre si, que o fato de o acolhimento constituir-se uma "atividade" oferecida pela unidade não impede que se estabeleça uma relação acolhedora em todos os espaços e momentos da produção de serviços de saúde, entre a equipe como um todo e os usuários (tanto aqueles representados pela demanda espontânea quanto aqueles que não procuram o serviço, mas também necessitam de atenção).

Compreendemos que há que se ter cuidado com uma questão importante na adoção da segunda forma de compreender e operacionalizar o acolhimento nos serviços de saúde: o fato de haver um espaço específico e uma equipe específica para o acolhimento pode des-responsabilizar o restante da equipe por estabelecer relações acolhedoras e de investigação das necessidades de saúde e comprometimento com sua satisfação nos demais espaços de encontro e de atenção à saúde.

\section{Metodologia}

Trata-se de um estudo que se orientou pela abordagem qualitativa de pesquisa, por entendermos que o objeto em estudo é histórico e social, constituído por processos de trabalho cuja complexidade e dinâmica só podem ser compreendidas de forma abrangente por suas dimensões qualitativas. Os dados foram coletados de dezembro/2003 a janeiro/2004, pelas observações participantes e entrevistas semi-estruturadas. $\mathrm{O}$ trabalho de campo desenvolveu-se em cinco centros de saúde do Município de Campinas, sendo um por distrito de saúde. Em cada um, foi observado o trabalho da equipe de enfermagem nos diferentes períodos e durante, pelo menos, três dias. O grupo que participou das entrevistas é composto por quatro auxiliares de enfermagem, sete enfermeiras, quatro coordenadoras (sendo três enfermeiras e uma odontóloga), totalizando quinze entrevistadas.

Com relação à análise dos dados, adotamos os passos operacionais propostos por Minayo 8: ordenação, classificação e análise final dos dados. Iniciamos fazendo organização inicial dos dados, agrupando os que diziam respeito a temas afins obtidos nas entrevistas e nos registros do diário de campo, para possibilitar o contraponto entre a perspectiva dos sujeitos e a observação do concreto do trabalho. Procedemos à leitura exaustiva dos dados, estabelecendo um esboço inicial das categorias de análise pela interação entre empírico e teórico. Em seguida, fizemos a priorização dos temas mais relevantes de acordo com o objeto de estudo, organizando os dados na categoria de análise.

Foram observados rigorosamente todos os aspectos éticos envolvidos na pesquisa com seres humanos, conforme proposto pela Resolução n. 196/96 do Conselho Nacional de Saúde. Os trabalhadores das unidades aceitaram participar do estudo, assinando o Termo de Consentimento Livre e Esclarecido. Além disso, foi solicitada autorização para a pesquisa aos coordenadores das unidades e à Secretaria Municipal de Saúde. O projeto foi submetido à análise pelo Comitê de Ética em Pesquisa da Faculdade de Ciências Médicas, Universidade Estadual de Campinas, em outubro/2003, tendo sido aprovado pelo parecer n. 50603.

\section{Diferentes concepções dos trabalhadores acerca do acolhimento}

Cada centro de saúde pesquisado apresentava particularidades na organização do que se denominava acolhimento. Concepções, formas dife- 
rentes, particulares, de organizar e fazer acolhimento, não apenas no que se refere a cada um dos cinco serviços, mas, com freqüência, diferentes mesmo entre equipes e trabalhadores dentro da própria unidade.

A primeira diferenciação que faremos é quanto à concepção acerca do que é acolhimento. Em quatro centros de saúde (São Marcos, São Cristóvão, Paranapanema e Ipaussurama), o acolhimento era considerado uma atividade oferecida à população, um tipo supostamente novo de atendimento no cardápio de opções do centro de saúde para atender às necessidades da população. Apenas na unidade Joaquim Egídio o acolhimento era considerado não uma atividade, mas uma forma diferente de fazer em todos os setores da unidade, uma postura ou atitude diante do usuário e de suas necessidades.

\section{O acolhimento nos centros de saúde São Marcos, São Cristóvão, Paranapanema e Ipaussurama}

\section{Formas de organizar o processo de trabalho}

Para atender a demanda dos usuários com "queixas” e que não estão agendados, os centros de saúde organizaram-se de formas diferentes e, em geral, passaram por diversas tentativas de organização. Apesar das particularidades de cada um, havia uma característica comum às unidades São Cristóvão, São Marcos e Ipaussurama: o acolhimento aparecia como um atendimento prestado pelo auxiliar de enfermagem para avaliar a queixa do usuário e decidir "se ele vai passar no médico naquele dia ou não”, ou seja, se a demanda que ele traz requer um encaixe nas "vagas de acolhimento" na agenda diária dos médicos ou se é possível agendar uma consulta médica de rotina.

No Centro de Saúde Paranapanema, a concepção sobre acolhimento pareceu-nos um pouco diferente. Pelo que pudemos observar na entrevista com a coordenadora, o acolhimento seria a primeira consulta com o médico e o atendimento feito pela enfermagem no acolhimento seria apenas uma forma de suprir a falta de médico ou os casos em que a agenda de vagas de acolhimento já estivesse esgotada e fosse necessário um atendimento imediato.

Nesse centro de saúde, as auxiliares de enfermagem ou os enfermeiros não ficaram responsáveis pelo acolhimento, porque o acolhimento aparentemente ficou sendo sinônimo de consulta médica eventual, sem agendamento. Ainda assim, a enfermagem tinha seu papel de recepção da demanda dos usuários, afinal, avaliavam ini- cialmente a queixa na recepção e, depois, agendavam a consulta. Nos casos em que não havia mais vagas, chamavam um dos enfermeiros para atender.

O acolhimento, como vimos, poderia ampliar a possibilidade de intervenção dos outros profissionais do centro de saúde que não o médico, ou seja, ampliar o cardápio de ofertas da unidade para atender as necessidades de saúde da população buscando romper com uma lógica médico-centrada. Supostamente, o acolhimento deveria ampliar a resolubilidade dos outros profissionais, notadamente a enfermagem, numa perspectiva de que as necessidades de saúde da população não podem nem devem ser atendidas exclusivamente por meio da consulta médica.

Entretanto, não notamos essa conseqüência do acolhimento nessas quatro unidades pesquisadas. A enfermagem ficou, de fato, responsável pelos acolhimentos nesses quatro centros de saúde, porém o enfoque percebido por nós foi o da realização de triagem: a função da enfermagem no acolhimento era basicamente escutar a queixa e avaliar a necessidade de consulta médica. $\mathrm{Na}$ verdade, a enfermagem estava cumprindo o papel de atender toda a demanda espontânea, ou a parte dela que não cabia diretamente na agenda médica, e avaliar os casos que requeriam consulta médica imediata ou que poderiam aguardar vaga na agenda.

A própria normalização de que as auxiliares de enfermagem não poderiam estabelecer conduta nenhuma sozinhas, ou de que auxiliares e enfermeiras não poderiam dispensar usuários com queixa sem avaliação médica, acabou restringindo a possibilidade de atuação da equipe de enfermagem e manteve uma lógica centrada nos saberes e práticas médicos. $\mathrm{O}$ acolhimento aparece como uma outra atividade de apoio ao trabalho médico, que facilita esse trabalho, organiza, e que acaba por reproduzir a lógica hegemônica, ao invés de superá-la.

\section{Acolhimento como garantia de acesso e ampliação da demanda}

Nas quatro unidades, houve referência ao fato de que a implementação da proposta de acolhimento garantiu uma ampliação do acesso ao serviço, com diminuição (ou mesmo eliminação) das filas e incorporação de parcela significativa da população que estava excluída das unidades, quando estas funcionavam na lógica anterior - da distribuição de senhas de acordo com a quantidade de consultas de eventuais disponíveis no dia, da inexistência de avaliação da necessidade da consulta, nos dias de abertura de agenda. 
Nessas unidades, em que o acolhimento é entendido majoritariamente como um serviço, ele tem representado justamente a resposta da unidade buscando atender, de alguma forma, a todos os usuários que procuram o serviço. Freqüentemente, não só nas entrevistas, mas durante a observação do trabalho nas unidades, os trabalhadores afirmam que "ninguém pode ser mandado embora sem um atendimento". Com isso, há também um aumento da demanda de trabalho e a necessidade de alternativas de encaminhamento para essa demanda, resultando, conseqüentemente, em aumento do trabalho na unidade, no mínimo do ponto de vista do número de atendimentos.

Olhando especificamente para o trabalho de enfermagem, é possível identificar essa questão, em especial, quando se analisam as falas e as práticas dos auxiliares de enfermagem. Nas quatro unidades a que nos referimos, o atendimento dos acolhimentos tem ficado, predominantemente, a cargo dos auxiliares de enfermagem. Há também um aumento da demanda de avaliações e consultas extras por parte dos médicos e de supervisão desse trabalho dos auxiliares (no que diz respeito, especialmente, ao esclarecimento de dúvidas e avaliação de casos mais complexos) pelos enfermeiros. No entanto, quem tem recebido e atendido a maior parte dessa demanda "nova" das unidades são os auxiliares de enfermagem, tanto na recepção (nos centros de saúde onde ela continua sendo a porta de entrada), quanto nos acolhimentos enquanto atendimentos de enfermagem à demanda espontânea.

Seis das sete enfermeiras entrevistadas e dois outros que não foram entrevistados (mas que relataram suas atividades durante a observação) afirmaram que o acolhimento está entre as três atividades que mais fazem - pelo que pudemos observar, referem-se à realização do atendimento propriamente dito, bem como à demanda por orientação e supervisão nos atendimentos realizados pelos auxiliares de enfermagem.

Logo, a enfermagem esteve bastante envolvida no processo de implantação do acolhimento nas unidades e os trabalhadores da enfermagem ficaram responsáveis pela maior parte das atividades que vinham sendo denominadas acolhimento nos Centros de Saúde São Marcos, São Cristóvão, Ipaussurama e Paranapanema.

Transformações no trabalho de enfermagem por referência ao acolhimento

A incorporação do acolhimento à dinâmica dos centros de saúde trouxe transformações ao processo de trabalho de enfermagem, conseqüências do aumento da demanda, mas não apenas.
Ainda que o acolhimento permaneça sendo entendido predominantemente como um dispositivo, ainda que funcione em uma lógica médico-centrada, marcado pela baixa resolubilidade e baixa autonomia da enfermagem, não há como negar que rearranjou a prática de enfermagem nas unidades.

Uma conseqüência importante trazida pelo acolhimento parece ser a re-significação do trabalho para os auxiliares de enfermagem. $\mathrm{O}$ atendimento de enfermagem prestado no acolhimento, nas diferentes formas em que ele foi organizado em cada unidade, trouxe novas possibilidades para o cotidiano do trabalho do auxiliar de enfermagem, incorporando algum grau de satisfação e conferindo um novo significado ao trabalho, na perspectiva das entrevistadas.

Uma das auxiliares entrevistadas, afirmou que, depois de cinco anos "fazendo a dispensação de medicamentos na farmácia", o acolhimento trouxe para ela uma nova possibilidade, que a fez sentir-se mais capacitada, mais autônoma e mais segura. De um trabalho monótono, restrito, com pouco espaço para a interação com o usuário e pequena relação com o que se idealiza como "trabalhar em saúde", ela passou a fazer atendimentos, ouvir, ajudar, passou a relacionar-se diretamente com os usuários, a supostamente resolver problemas e dar respostas a necessidades.

Essa é uma dimensão importante a se considerar - a satisfação dos trabalhadores com a sua prática, agora mais dotada de sentido, na percepção deles. De alguma forma, o trabalho do auxiliar qualifica-se, passa a integrar mais efetivamente o trabalho em equipe, a prática deixa de ser restrita apenas ao atendimento individual, fragmentado, e os auxiliares passam a enxergar mais nitidamente o produto do seu trabalho. E, por isso mesmo, sentem-se e são mais reconhecidos e valorizados (pela equipe e pelos usuários). O trabalhador desaliena-se em alguma medida e, juntamente com o usuário-cidadão, atua como sujeito responsável pela interação de ambos.

Contudo, essa satisfação e essa preferência dos trabalhadores de enfermagem pelo trabalho com o acolhimento não é consenso. Na percepção dos entrevistados, a razão da insatisfação de alguns trabalhadores da enfermagem com o trabalho reorganizado para incorporar o acolhimento reside, justamente, na referência à sobrecarga de trabalho.

Além do aumento da demanda em termos da quantidade de usuários chegando ao serviço, há um aumento do trabalho de outra ordem - um aumento "qualitativo", digamos. Uma das coordenadoras de unidade fez uma análise interessante do que poderia estar causando essa percepção de sobrecarga de trabalho por parte dos trabalhado- 
res. No seu entender, a equipe considera o trabalho no acolhimento muito complexo e, quando questionada sobre a razão dessa percepção da equipe, afirmou que essa complexidade relaciona-se à exigência do trabalho em equipe, para a resolução dos problemas identificados pelo acolhimento; à necessidade de comprometimento do trabalhador com o usuário, por causa da escuta da demanda trazida por ele; e ao sofrimento decorrente da responsabilidade por acolher (e supostamente dar resposta a) os problemas e as necessidades dos usuários.

O auxiliar de enfermagem, na maioria das vezes, foi designado como o trabalhador responsável pelo acolhimento, enquanto etapa do processo de trabalho. Como vimos, quando se atribui um responsável, quando se estabelece que o acolhimento é uma etapa do processo de trabalho na unidade, um atendimento (com um lócus específico, um trabalhador específico), o resultado, muito provavelmente, é o descomprometimento do restante da equipe. $\mathrm{O}$ acolhimento deixa de ser responsabilidade de todos, deixa de ser uma atitude da equipe, do serviço, diante do usuário e suas demandas (as declaradas e as não declaradas), e passa a ser apenas mais um procedimento; perdendo o potencial de dispositivo de gestão para a reorganização do processo de trabalho, numa perspectiva crítica e comprometida com as necessidades da população. E tal procedimento, de recepção qualificada, conformou-se como atribuição da enfermagem, destacadamente do auxiliar de enfermagem.

O trabalhador que está no acolhimento ouve a demanda, a queixa, o problema, a necessidade do usuário que está ali, na sua frente, e é responsável por dar algum tipo de resposta. Da forma como o acolhimento foi organizado e tem acontecido freqüentemente nas unidades, dificilmente o auxiliar de enfermagem consegue dar essa resposta sozinho. E essa impossibilidade não é pautada apenas pelos limites determinados pela competência técnica esperada de um auxiliar de enfermagem. Obviamente os limites são também de outras ordens: a falta de capacitação específica para o acolhimento, a inexistência de protocolos que orientem o atendimento das queixas comuns, a exigência (estabelecida em algumas unidades) de avaliação médica para todos os atendimentos realizados por auxiliar de enfermagem, a falta de um cardápio mais amplo de opções para encaminhamento das demandas identificadas, restrito apoio e participação da equipe multiprofissional, entre outros tantos.

Além disso, considerando que o trabalho em saúde (e, conseqüentemente, na enfermagem) tem obedecido a uma lógica centrada no trabalho médico e no procedimento, desviando-se de seu foco - o usuário e suas necessidades de saúde - e que a relação entre trabalhadores e usuários dos serviços de saúde tem se realizado de forma mecânica e superficial, restrita à produção de procedimentos e consultas, verificamos que o trabalho de enfermagem vem funcionando numa lógica de "tocar o serviço", "fazer atendimentos", em que a maioria de seus agentes não olha e não ouve o usuário e suas necessidades e não se compromete, de fato, com o atendimento dessas necessidades 7 . Se o trabalhador, com o acolhimento, passa a ouvir e está colocado numa posição de responsável por desencadear algum tipo de resposta, de solução para o problema identificado, cria-se, então, uma situação de maior envolvimento.

Temos, em um momento anterior, uma auxiliar de enfermagem que está na recepção de uma unidade básica atendendo um usuário que vem ao serviço trazendo um problema de saúde que espera que seja resolvido. E essa auxiliar responde que não há consulta e que ele deve voltar em outro dia. Pela implantação do acolhimento, temos uma auxiliar de enfermagem que atende esse mesmo usuário, em um dado lugar, senta-se frente a frente e pergunta qual é o problema, ouve, anota no prontuário e vai atrás do enfermeiro ou do médico para avaliar. Embora essa segunda auxiliar não esteja acolhendo de fato no sentido de atender, responder, personalizar e orientar 7, embora se trate apenas de uma recepção qualificada, ainda distante do estabelecimento ideal de vínculo e responsabilidade, o trabalho desenvolvido por ela e pela equipe de saúde é maior, talvez inclusive melhor.

A recepção dos centros de saúde comumente foi e continua sendo considerada um lugar difícil de trabalhar. Quem está ali é responsável por receber todos os usuários que chegam, com suas diferentes demandas e encaminhá-los dentro das alternativas existentes no serviço. E quando não há alternativa? E quando não há consulta? E se não há nada a lhes oferecer? Tradicionalmente a recepção é um lugar de conflito, não sendo difícil encontrar relatos ou presenciar situações de agressão verbal e mesmo física, porque de um lado há alguém que traz uma demanda que entende que deveria ser atendida pelo serviço e que lhe parece importante, urgente e merecedora de uma resposta imediata, e de outro há um trabalhador que não tem nada a oferecer, não dispõe ou não consegue enxergar outras ofertas e não se sente responsável por essa falta de opção.

Quando o acolhimento se estrutura como uma recepção melhorada, aparentemente a dificuldade, para os trabalhadores, aumenta. Eles têm que atender a todos e têm de ouvi-los. Essa escuta - por mais que seja meramente ouvir o 
que o outro diz, por mais que não seja "escuta qualificada” - traz uma implicação, uma responsabilidade para o trabalhador. O trabalhador perguntou qual era o problema, o usuário contou. $\mathrm{E}$ agora?

Quando o serviço abre um canal de escuta com o usuário, abre uma possibilidade para que as pessoas tragam, para dentro do centro de saúde, as suas queixas, os seus problemas e as suas necessidades. Nem sempre é fácil ouvir. É mais fácil trabalhar com uma "queixa clínica", uma parte do corpo que dói, uma doença que precisa de medicamento. Quando abrimos um espaço para o diálogo com o usuário, por mais reduzido que ele seja, abrimos uma porta para que a "vida lá fora" entre na dinâmica do trabalho da unidade.

Acolher não é simples e demanda energia. A partir da instauração do acolhimento, aquelas pessoas que eram dispensadas na recepção, que não tinham suas demandas atendidas e com as quais o serviço e os trabalhadores não se comprometiam (muitas sequer tinham acesso à recepção), passam a ser ouvidas em espaço físico mais reservado e têm a oportunidade de falar de seus problemas com um profissional de saúde.

Freqüentemente, o trabalhador que está na recepção do centro de saúde não vai ter respostas para dar, não vai ter soluções para aqueles problemas, por inúmeras razões. O serviço não oferece opções, não há como encaminhar para outro local, não há colaboração da equipe, o trabalhador não identifica as opções que existem, a natureza dos problemas foge ao alcance do trabalhador e do serviço. Isso gera angústia. Passar o dia ouvindo queixas, problemas, necessidades da população (às vezes, "horríveis") e não saber ou não ter como resolvê-los é a situação comumente referida pelo trabalhador do acolhimento.

Os trabalhadores assumem maiores responsabilidades, alguns, inclusive, como vimos, sentem-se valorizados e reconhecidos por isso; todavia essas responsabilidades podem representar um sofrimento. Pessoas que escolheram o trabalho de cuidar de outras pessoas, ajudandoas, que entendem que seu objetivo é "melhorar a vida das pessoas", "ajudar os pacientes", "fazer com que eles fiquem mais saudáveis" etc., vêemse "acolhendo" muitos problemas de muitas pessoas, mas, freqüentemente, sentem-se incapazes de resolvê-los. E, na maior parte do tempo, não contam com apoio institucional e supervisão para trabalhar tais questões.

\section{Humanização}

As falas de algumas entrevistadas destacam a humanização como uma mudança positiva e resul- tante da inserção do acolhimento na dinâmica do trabalho nas unidades. Em geral, essas falas apontam na direção da humanização do acesso, mais precisamente da humanização da recepção, da porta de entrada do serviço.

No Centro de Saúde São Marcos, as entrevistadas destacaram que a mudança ocorrida na recepção foi fundamental para a transformação da relação entre trabalhadores e usuários. A retirada da grade da recepção e a possibilidade de receber os usuários numa sala, ouvir o que eles têm a dizer, avaliar a queixa, oferecer as possibilidades disponíveis, mesmo que essas ainda sejam restritas, aparece como fator desencadeador de uma relação mais respeitosa entre trabalhadores e usuários. O serviço passa a receber os usuários de uma outra forma, com mais espaço para o diálogo, e os usuários se sentem mais "acolhidos", o que diminui a ocorrência de conflitos e agressões, mesmo havendo ainda espera e falta de vagas.

Mesmo quando a mudança na relação entre trabalhadores e usuários não foi tão significativa quanto a percebida pelas entrevistadas no Centro de Saúde São Marcos, a ampliação do acesso em si é entendida como fator "humanizante" da relação entre o serviço e os usuários.

As mudanças apontadas nas entrevistas parecem indicar que o acolhimento, do modo como se estruturou nas unidades, contribuiu para "humanizar" as ações de recepção dos usuários e suas demandas no serviço. A garantia do acesso e a abertura de um canal de diálogo, com base no acolhimento, são identificados pela equipe como responsáveis pelo estabelecimento de uma relação mais respeitosa com os usuários, de reconhecimento das demandas, das necessidades e do sofrimento das pessoas que recorrem ao serviço de saúde como instituição socialmente reconhecida como responsável pela solução dessas questões.

Entendemos que "humanizar" as relações entre usuários e trabalhadores, conseqüentemente "humanizando" o processo de produção de serviços de saúde, significa reconhecer os sujeitos como dotados de desejos, necessidades e direitos. A finalidade última do processo de trabalho em saúde é justamente a produção de algo - a ação de saúde - que responda a necessidades de saúde dos usuários. Reconhecê-los como sujeitos significa comprometer-se com a satisfação de necessidades, entendendo a saúde como um direito, pela construção de relações de acolhimento, vínculo e responsabilização. Nas palavras de Puccini \& Cecílio 9 (p. 1350), é necessário que se criem "formas que materializem social e politicamente uma ação cuidadora integral, como direito de cidadania". 
A humanização da recepção com o acolhimento, nesse sentido indicado pelas entrevistadas, e a ampliação do acesso são questões importantes na construção de modelos de atenção à saúde centrados no usuário e suas necessidades de saúde, no entanto, definitivamente, não esgotam o conceito de humanização num sentido mais amplo, de reconhecimento da saúde como direito das pessoas e de busca contínua da satisfação de necessidades de saúde.

\section{O acolhimento no Centro de Saúde Joaquim Egídio}

No Centro de Saúde Joaquim Egídio, o acolhimento não é encarado como uma etapa do processo de trabalho, não se configurou como uma atividade ou serviço novo oferecido à população. O acolhimento é entendido como uma postura, uma forma de receber e atender os usuários em qualquer momento de interação entre a equipe e a população, no sentido do que é proposto por Teixeira 6. Então, fala-se em acolher na sala de vacina, na recepção, na visita domiciliária, na consulta de enfermagem, na dispensação de medicamentos.

Nas entrevistas, o acolhimento aparece como a escuta das demandas do usuário, bem como a investigação de riscos e das necessidades de saúde, além do comprometimento com a resolução das questões trazidas pelo usuário ou identificadas pelo trabalhador.

Uma outra concepção do acolhimento que também permeia os discursos dos trabalhadores, tanto durante as entrevistas quanto na observação do trabalho, é a de que o acolhimento tem como um importante objetivo dar respostas às necessidades dos usuários que não sejam clínicas, que dizem respeito ao que Cecílio 10 (p. 115) denomina necessidade de "vínculos (a)efetivos entre cada usuário e uma equipe elou profissional".

A equipe de enfermagem do Centro de Saúde Joaquim Egídio demonstra predominantemente ter a concepção - presente também nas outras unidades - de que o acolhimento pode ser um momento de interação entre trabalhadores e usuários com a finalidade específica de lidar mais com a necessidade dos usuários de estabelecer vínculo com o trabalhador e equipe: necessidade de conversar, desabafar, falar dos problemas. Mesmo quando não há um "problema de saúde" instalado, no sentido mais restrito da expressão, como uma doença ou uma questão de ordem física que justifique a procura pelo serviço.

Assim como nos outros centros de saúde, essa percepção de que os usuários muitas vezes procuram o serviço buscando uma oportunidade para falar dos seus problemas e ser ouvido é comum no Centro de Saúde Joaquim Egídio. No entanto, há uma diferença fundamental entre essa unidade e as demais: há um esquema mais estruturado para atendimento dessa necessidade dos usuários. Pelo que pudemos observar e foi dito nas entrevistas, essa escuta no Centro de Saúde Joaquim Egídio diferencia-se das demais unidades, pois o trabalhador não escuta o que o usuário diz com o entendimento de que ele precisa apenas falar, como se a escuta, pura e simples, fosse a resposta necessária. A partir dessa escuta inicial, se a equipe julga necessário, um trabalho de acompanhamento é desencadeado.

O Centro de Saúde Joaquim Egídio tem uma equipe que compõe o Núcleo de Saúde Mental da unidade, que tem como objetivo justamente acompanhar esses casos, fazendo o que eles chamam de aconselhamento e também avaliando a necessidade de encaminhamento para consulta de psicologia ou psiquiatria, quando é o caso. Essa equipe é formada por uma enfermeira, uma auxiliar de enfermagem, uma agente comunitária de saúde e uma médica clínica geral e conta com o apoio matricial de uma psicóloga de um centro de saúde próximo.

Podemos entender, portanto, que os trabalhadores identificam necessidades nesse sentido e, a partir daí, caso julguem necessário, assumem seu acompanhamento ou encaminham-no para os profissionais que compõem o Núcleo de Saúde Mental e que acabaram se tornando referência para o atendimento desses usuários. Pela fala da enfermeira do centro de saúde, a idéia inicial era de que toda a equipe fizesse esse tipo de acompanhamento dos usuários que necessitassem. No entanto, a constituição do núcleo acabou por criar uma cultura de encaminhamento para aqueles que estão mais envolvidos com esse trabalho ou que são considerados mais disponíveis e capacitados, e por isso mesmo o integram.

Logo, o acolhimento no Centro de Saúde Joaquim Egídio se configura como uma atitude diante do usuário - de escuta, investigação de necessidades, responsabilização com o oferecimento de uma resposta a essas necessidades.

\section{Conclusão}

O acolhimento apareceu, predominantemente, como garantia de acesso à recepção das unidades e de humanização dela, tendo sido entendido enquanto uma postura diante das necessidades dos usuários em todos os momentos de encontro dele com o serviço em apenas uma unidade estudada. Pelo modo como se operacionalizou 
em quatro das unidades pesquisadas, o acolhimento acabou por favorecer somente o atendimento da demanda espontânea e configurou-se muito mais como um pronto-atendimento para as queixas agudas do que como um fator desencadeador de transformações no processo de trabalho ou da construção de relações entre trabalhadores e usuários baseadas na solidariedade e no compromisso com a identificação e satisfação das necessidades de saúde. Por conseguinte, pode ser considerado não mais do que um novo "procedimento" de recepção, sem ter conseguido desencadear novas posturas ou configurar-se como um dispositivo de análise e gestão.

\section{Resumo}

O presente artigo relata as transformações no trabalho da enfermagem com a incorporação do acolhimento no processo de implementação do Projeto Paidéia de Saúde da Família na Secretaria Municipal de Saúde de Campinas, São Paulo, Brasil, a partir de 2001. Apresenta os dados obtidos por intermédio da realização de observação participante e entrevistas semiestruturadas na investigação do processo de trabalho de enfermagem por referência ao acolhimento. Baseia suas análises na existência de dois modos diferentes de pensar e operacionalizar o acolhimento: como postura diante dos usuários e suas necessidades e como um dispositivo capaz de reorganizar o processo de trabalho. Além disso, analisa o acolhimento com base nas seguintes questões: organização do processo de trabalho, garantia de acesso, ampliação da demanda, transformações no trabalho de enfermagem, humanização e vínculo.

Acolhimento; Enfermagem; Programa Saúde da Família
Devemos, no entanto, destacar que algo já se conquistou na direção do reconhecimento da saúde como um direito. No mínimo, quando se amplia o acesso, reduzem-se as filas de espera e aumenta-se o respeito pela dor e dificuldades dos usuários dos serviços. Contudo, reiteramos que a consolidação dos avanços alcançados com a implantação do acolhimento demanda que os agentes de tal trabalho sejam atendidos em suas necessidades de educação permanente, supervisão e apoio institucional a fim de que o trabalho que realizam seja qualificado de forma inequívoca.

\section{Colaboradores}

M. L. S. Takemoto e E. M. Silva participaram conjuntamente da concepção do artigo, da análise nele contida e da revisão do texto final. 


\section{Referências}

1. Takemoto MLS. O trabalho de enfermagem em centros de saúde e a mudança do modelo de atenção no Município de Campinas - SP [Dissertação de Mestrado]. Campinas: Faculdade de Ciências Médicas, Universidade Estadual de Campinas; 2005.

2. Merhy EE. Em busca do tempo perdido: a micropolítica do trabalho vivo em saúde. In: Merhy EE, Onocko R, organizadores. Agir em saúde: um desafio para o público. São Paulo: Editora Hucitec/ Buenos Aires: Lugar Editorial; 1997. p. 74-111.

3. Franco TB, Bueno WS, Merhy EE. O acolhimento e os processos de trabalho em saúde: o caso de Betim (MG). In: Merhy EE, Magalhães Jr. HM, Rimoli J, Franco TB, Bueno WS, organizadores. O trabalho em saúde: olhando e experienciando o SUS no cotidiano. São Paulo: Editora Hucitec; 2003. p. 37-54.

4. Schimit MD, Lima MADS. Acolhimento e vínculo em uma equipe do Programa Saúde da Família. Cad Saúde Pública 2004; 20:1487-94.

5. Silva Jr. AG, Mascarenhas MTM. Avaliação da atenção básica em saúde sob a ótica da integralidade: aspectos conceituais e metodológicos. In: Pinheiro R, Mattos RA, organizadores. Cuidado: as fronteiras da integralidade. Rio de Janeiro: ABRASCO/ São Paulo: Editora Hucitec; 2004. p. 241-57.
6. Teixeira RR. O acolhimento num serviço de saúde entendido como uma rede de conversações. In: Pinheiro R, Mattos RA. Construção da integralidade: cotidiano, saberes e práticas em saúde. Rio de Janeiro: Instituto de Medicina Social, Universidade do Estado do Rio de Janeiro/ABRASCO; 2003. p. 49-61.

7. Camelo SHH, Angerami ELS, Silva EM, Mishima SM. Acolhimento à clientela: estudo em unidades básicas de saúde no Município de Ribeirão Preto. Rev Latinoam Enfermagem 2000; 8:30-7.

8. Minayo MCS. O desafio do conhecimento: pesquisa qualitativa em saúde. 7a Ed. São Paulo: Editora Hucitec/Rio de Janeiro: ABRASCO; 2000.

9. Puccini PT, Cecílio LCO. A humanização dos serviços e o direito à saúde. Cad Saúde Pública 2004; 20:1342-53.

10. Cecílio LCO. As necessidades de saúde como conceito estruturante na luta pela integralidade e eqüidade na atenção em saúde. In: Pinheiro R, Mattos $\mathrm{RA}$, organizadores. Os sentidos da integralidade na atenção e no cuidado à saúde. Rio de Janeiro: Instituto de Medicina Social, Universidade do Estado do Rio de Janeiro/ABRASCO; 2001. p. 113-26.

Recebido em 29/Set/2005

Aprovado em 02/Mai/2006 